\title{
SLIP-SHAKEDOWN ANALYSIS AND THE ASSUMPTION OF SMALL COUPLING IN FRICTIONAL CONTACT
}

\author{
Nicolas Antoni ${ }^{1}$, Quoc Son Nguyen ${ }^{2}$ \\ ${ }^{1}$ Teuchos SA, Deptment of Mecanique des Structures \\ 78180 Montigny le Bretonneux, France \\ ${ }^{2}$ Laboratoire de Mecanique des Solides, CNRS umr7649 \\ Ecole Polytechnique, 91128 Palaiseau, France
}

\begin{abstract}
In the frictional contact of solids under cyclic loads, the shakedown behaviour of the relative displacement is of interest in the same spirit as the plastic deformation in plasticity. Cumulative slips may lead to the failure due to large relative displacements of the components of an assembly while cyclic slips are often undesired because of wear and fretting ufatigue problems. Under Coulomb friction, it is well known that Melan and Koiter theorems are generally not available, except in certain particular cases. In this discussion, the particular case of small coupling between the contact pressures and the slip-displacements is considered. This assumption means that the tangent displacements have small or no influence on the contact pressures which can be then computed from the elastic response as in the uncoupling case. The pressure is thus a given time-dependent function and the Coulomb criterion is reduced to a Mises-like standard law of friction. It is shown here that Melan and Koiter theorems can be applied again as in standard plasticity. The dependence of the yield limit on the loading amplitude is however not classical and the extension of the static and kinematic approaches is discussed to obtain the critical shakedown load or the limit load. The validity of the assumption of small coupling is also explored by numerical simulation in an practicle example.
\end{abstract}

\section{INTRODUCTION}

The mechanical behaviour of a system of solids in frictional contact under cyclic loads and pre-stresses is considered here. In particular, the response may lead to undesired effects such as the failure by unbounded slips of the solids in contact or to the fatigue damage by alternating slips. The slips may also shakedown in the sense that the slip vector at any point of the contact surface tends to a finite limit at large time. The conditions ensuring the slip-shakedown of the system are of interest in many engineering structures.

Some interesting discussions on the subject can be found in the literature, cf. [2], [1], [5]. The problem of slip-shakedown has been discussed in several examples of engine components under periodic thermo-mechanical loadings, cf. [2], and the analogy of this phenomenon with the elastic-plastic response of structures has been pointed out, especially 
concerning the possibility of shakedown and the validity of Melan and Koiter theorems when the friction criterion does not depend on the normal pressure (Mises-like friction). For Coulomb friction, the validity of Melan theorem has been recently discussed, cf. [3] [5], under the assumptions of full contact and of uncoupling of the normal pressures versus the tangent slips. Since such a condition is rather restrictive for most common structures, it is interesting to analyze the magnitude of the coupling. In particular, if the coupling effect is small enough, these results can be applied as an approximation. Since the dependence of the yield force on the loading amplitude is not classical, the objective of this paper is to discuss in this case the validity of Melan and Koiter theorems and to show how the static and kinematic approaches can be extended in this framework to obtain the critical shakedown load or the limit load. The validity of the assumption of small coupling is also explored by numerical simulation in the example of a car-ưengine conrod submitted to a rotating load.

\section{SOLIDS IN FRICTIONAL CONTACT UNDER CYCLIC LOAD}

\subsection{Governing equations}

A system of two elastic solids is considered to describe the relative displacement problem. A solid $V_{2}$ is assumed to be elastic (or rigid) and maintained by prescribed displacements $\mathbf{u}_{\mathbf{d}}=\mathbf{0}$ on a portion $S_{u}$ of its boundary. A second elastic solid of volume $V_{1}$ is maintained only by an unilateral and frictional contact on a common portion $S_{c}$ of the boundaries. The two solids are submitted to a mechanical loadings composed of the fields of volume force $\mathbf{f}(t)$ and surface force $\mathbf{F}(t)$ on the complementary portions of the boundaries $\left(S_{1}^{f}=S_{1}-S_{c}\right.$ and $\left.S_{2}^{f}=S_{2}-S_{u}-S_{c}\right)$ for $0 \leq t \leq+\infty$. The existence of a pre-stress field $\sigma_{o}$ in $V_{i}$ is also admitted.

The normal and tangent relative displacements of $V_{2}$ with respect to $V_{1}$ on $S_{c}$ is denoted as $W$ and $U$ and the friction force and the contact pressure acting by $V_{1}$ on $V_{2}$ are denoted as $q$ and $p$ respectively. On the contact surface $S_{c}$, the unilateral contact conditions and Coulomb law of friction must be satisfied. This means that

$$
\begin{gathered}
W \geq 0, p \geq 0, p W=0 \\
\phi=\|q\|-k \leq 0, k=\varphi p, \dot{U}=\lambda Q, \lambda \geq 0, \phi \lambda=0 .
\end{gathered}
$$

In a quasi-static transformation starting from a given initial value $\mathbf{U}_{o}$, the response of the system (in displacements $u(t)$, in stresses $\sigma(t)$ ) is governed by the system of equations:

$$
\left\{\begin{array}{l}
\nabla \cdot \sigma+f=0, \\
\sigma=\sigma_{o}+L: \nabla u \text { in } V=V_{1} \cup V_{2}, \\
\sigma \cdot n=F \text { on } S^{F}, u=0 \text { on } S_{1}^{u} \\
W=[u] \cdot n, U=[u]-W n, q=\sigma \cdot n-(n \cdot \sigma \cdot n) n, p=n \cdot \sigma \cdot n \\
+ \text { Unilateral contact condition } \\
+ \text { Coulomb law of friction } \\
\text { + Initial conditions in position. }
\end{array}\right.
$$

where $[u]$ is the relative displacement of the two solids and $n$ denotes the outward normal vector to $V_{1}$ on $S_{c}$. 
This cumbersome problem presents some similarity with incremental plasticity. Indeed, the slip-displacements can be understood as localized plastic strains on the contact surface $S_{c}$. The possibility of shakedown or alternating sliding or cumulative sliding under cyclic loadings can be observed and discussed as in plasticity. In particular, under the assumption of no separation, it has been pointed out that Melan and Koiter theorems hold as in classical plasticity [1] when the friction coefficient $\varphi=0$ i.e. for a pressureindependent laws of friction. In particular, for an associated Mises-like law of friction of the form $\phi=\|q\|-k(x, t) \leq 0$, these classical results are available even if $k(x, t)$ is a given function of time.

\subsection{The assumption of small coupling}

Unfortunately, this possibility does not hold for a pressure-dependent law of friction such as Coulomb friction. However, it has been shown recently, cf. [5], [3], that Melan's theorem still holds if there is no coupling of the contact pressure with respect to the tangent displacement. This condition can be written from the classical decomposition of the response of the system into the elastic response and the coupling response:

- The elastic response is the response of the system to the loading when there is stick contact:

$$
\left\{\begin{array}{l}
\nabla \cdot \sigma_{e \ell}+f(t)=0, \\
\sigma_{e \ell}=\sigma_{o}+L: \nabla u_{e \ell}, \text { in } V \\
\sigma_{e \ell} \cdot n=F(t) \text { on } S^{F}, u_{e \ell}=0 \text { on } S_{u} \\
{\left[u_{e \ell}\right]=0 \text { on } S_{c} \text { (stick contact) }}
\end{array}\right.
$$

in which the data are $\mathbf{f}(t), \mathbf{F}(t), \sigma_{o}$

- The coupling response (contact pressure/tangent slip) is the response of the system, assumed to be free of load, under a prescribed slip:

$$
\left\{\begin{array}{l}
\nabla \cdot \sigma^{*}=0, \\
\sigma^{*}=L: \nabla u^{*} \text { in } V \\
\sigma^{*} \cdot n=0 \text { on } S^{F}, u^{*}=0 \text { on } S_{u} \\
{\left[u^{*}\right] \cdot n=0,\left[u^{*}\right]=U^{*} \text { on } S_{c}}
\end{array}\right.
$$

in which the data are $\mathbf{U}^{*}$ and the response in displacement, stress and contact pressure are $\mathbf{u}^{*}, \sigma^{*}, \mathbf{p}^{*}$.

From these definitions, it is clear that the solution of (3) satisfies

$$
u=u_{e \ell}+u^{*}(U), \sigma=\sigma_{e \ell}+\sigma^{*}(U), p=p_{e \ell}+p^{*}(\mathbf{U})
$$

The local ratio of the coupling (contact pressure / tangent slip) associated with the solution of (3) can be defined as

$$
r(x, t)=\frac{\left\|p^{*}(U)(x, t)\right\|}{p(x, t)} .
$$

By definition, there is uncoupling if $r=0$ and small coupling if $r \ll 1$ for all $t$ and all $x \in S_{c}$. 
In particular, there is uncoupling for the considered system if $p^{*}=0$ for all $U^{*}$. Such assumption is satisfied for example in the problem of contact of a rigid punch on an elastic half-plane. The validity of Melan theorem and the analysis of shakedown have been discussed in [5], [3] for uncoupled systems. Since the assumption of uncoupling is generally not satisfied, the case of small coupling can also be of interest since this assumption enables us to consider the uncoupling case as an approximation and obtain a good estimate of the critical shakedown loads.

\section{SLIP-SHAKEDOWN ANALYSIS}

From (6) and from the assumption of small coupling (7), the Coulomb criterion of friction is modified and written as in the case of uncoupling

$$
\|q(x, t)\|-\varphi p_{e \ell}(x, t) \leq 0 .
$$

The modified criterion (8) is a Mises-like criterion and the Melan-Koiter framework can be thus applied for the approximate response. There is however a small difference with the classical description since in (8), the yield limit depends on the amplitude of the loading.

Let $S F$ be the space of tangent self-forces defined on $S_{c}$. By definition, a field of tangent forces $\mathbf{q}$ belongs to $S F$ if there exists a self-stress field $\sigma_{s}$ defined in V such that

$$
\left\{\begin{array}{l}
\nabla \cdot \sigma_{s}=0 \text { in } V \\
\sigma_{s} \cdot n=0 \text { on } S^{F} \\
{\left[\sigma_{s}\right] \cdot n=0 \text { on } S_{c}} \\
q=\sigma_{s} \cdot n-\left(n \cdot \sigma_{s} \cdot n\right) n \text { on } S_{c} .
\end{array}\right.
$$

A relative rigid displacement by tangent slips of the solids is eventually possible when the contact surface is a spherical or a cylindrical or a plane surface. Let $R S$ be the space of rigid slips i.e. of the slips due to relative rigid displacements of the two solids. By definition, $G \in R S$ if there exists at least a displacement field $\mathbf{u}$ such that

$$
\left\{\begin{array}{l}
\epsilon(u)=0 \forall x \in V, u=0 \text { on } S_{u}^{1} \\
{[u] \cdot n=0,[u]=G \text { on } S_{c} .}
\end{array}\right.
$$

In particular, the following orthogonality relation holds:

$$
\int_{S_{c}} q \cdot G d a=0, \forall q \in S F, \forall G \in S R .
$$

\subsection{Melan theorem}

Let $Q_{E L}(x)$ be the set of values of $q_{e \ell}(x, t)$ for all $t \geq 0$. Then a periodic loading path such that its associated elastic response $q_{e \ell}(x, t)$ is of arbitrary period $T$, taking all the values in $Q_{E L}(x)$ for $0 \leq t \leq T$ can be introduced to obtain the following statement which is a sufficient condition of slip-shakedown for all standard pressure-independent laws of friction, in the spirit of Melan theorem:

If there exists a time-independent tangent force $\mathbf{q}^{*} \in S F$ and a coefficient $m>1$ such that $\tilde{q}(x, t)=m\left(q^{*}(x)+q_{e \ell}(x, t)\right)$ satisfies for all $0 \leq t \leq T$ and for all $x \in S_{c}$ the modified criterion (8), then there is necessarily a shakedown of the slips whatever the initial conditions. 


\subsection{Safety coefficient and critical shakedown load}

As in the theory of plasticity, cf. [4] [6], a safety coefficient $m_{s}$ associated with a given loading (represented by the elastic response) for the slip-shakedown can be introduced:

$$
\left\{\begin{array}{l}
m_{s}=\max _{q^{*} \in S F} m \\
\text { such that } \tilde{q}(x, t)=m\left(q^{*}(x)+q_{e \ell}(x, t)\right) \text { satisfies } \\
\text { the modified criterion } \forall 0 \leq t \leq T \text { and } \forall x \in S_{c} .
\end{array}\right.
$$

It is clear that if $m_{s}>1$, then, there is a slip-shakedown from Melan theorem. The definition (12) leads to the resolution of a problem of optimization under convex constraints. As in plastic shakedown theory [4] [7], [8] an associated lagrangean can be introduced and leads by min-max duality to the kinematic expression of the safety coefficient

$$
\left\{\begin{array}{l}
m_{s}=\min _{\mathbf{g}} \int_{o}^{T} \int_{S_{c}} \varphi p_{\ell \ell}(x, t)\|g(x, t)\| d x d t \\
\text { among the slip rates } g(x, t) \text { such that } \\
\mathbf{G}=\int_{0}^{T} \mathbf{g} d t \in R S \\
\text { and that } \int_{o}^{T} \int_{S_{c}} q_{e \ell}(x, t) \cdot g(x, t) d x d t=1,
\end{array}\right.
$$

or equivalently

$$
\left\{\begin{array}{l}
m_{s}=\min _{\mathrm{g}} \frac{\int_{o}^{T} \int_{S_{c}} \varphi p_{e \ell}\|g\| d x d t}{\int_{o}^{T} \int_{S_{c}} q_{e \ell} \cdot g d x d t} \\
\text { among the slip rates } \mathbf{g} \text { such that } \\
\mathbf{G}=\int_{0}^{T} \mathbf{g} d t \in R S .
\end{array}\right.
$$

As in plasticity, the kinematic expression shows clearly two mechanisms of non-shakedown. The long-term slips may be alternative without final displacement $\mathbf{G}=0$ or become cumulative and lead to a final rigid displacement $\mathbf{G} \neq \mathbf{0}$.

From these general results, the approximation (8) leads then to an estimate of the critical load of shakedown and of the limit load for a loading defined by a constant field of prestress $\sigma^{o}$ and an external loading

$$
(f(x, t), F(x, t))=\mu\left(f^{\ell}(x, t), F^{\ell}(x, t)\right)
$$

proportional to a load factor $\mu$. In this case, the elastic leads to the following expressions

$$
q_{e \ell}(x, t)=q^{o}(x)+\mu q_{e \ell}^{\ell}(x, t), p_{e \ell}(x, t)=p^{o}(x)+\mu p_{e \ell}^{\ell}(x, t),
$$

where $p^{o}, q^{o}$ are due to the constant prestress and $p_{e \ell}^{\ell}, q_{e \ell}^{\ell}$ are due to the external loading. It is assumed that

$$
p^{o}(x)>0, p^{o}(x)+\mu p_{e \ell}^{\ell}(x, t)>0 \forall x \in S_{c}, \forall 0 \leq t \leq T .
$$

Let $m_{s}(\mu)$ be the safety coefficient associated with the load factor $\mu$. From (14), (16) and from (11), since $\mathbf{q}^{\mathbf{0}} \in S F$ the following expression holds

$$
\left\{\begin{array}{l}
m_{s}(\mu)=\min _{\mathbf{g}} \frac{\int_{o}^{T} \int_{S_{c}} \varphi\left(p_{o}(x)+\mu p_{e \ell}^{\ell}(x, t)\right)\|g(x, t)\| d x d t}{\int_{o}^{T} \int_{S_{c}} \mu q_{e \ell}^{\ell}(x, t) \cdot g(x, t) d x d t} \\
\text { among the slip rates } \mathbf{g} \text { such that } \\
\mathbf{G}=\int_{0}^{T} \mathbf{g} d t \in R S .
\end{array}\right.
$$


The critical load factor for shakedown $\mu_{s h}$ is defined by condition

$$
m_{s}\left(\mu_{s h}\right)=1
$$

or equivalently

$$
\left\{\begin{array}{l}
\mu_{s h}=\min _{\mathbf{g}} \int_{o}^{T} \int_{S_{c}} \varphi\left(p_{o}(x)+\mu_{s h} p_{e \ell}^{\ell}(x, t)\right)\|g(x, t)\| d x d t \\
\text { among the slip rates } \mathbf{g} \text { such that } \\
\mathbf{G}=\int_{0}^{T} \mathbf{g} d t \in R S \\
\text { and that } \int_{o}^{T} \int_{S_{c}} q_{e \ell}^{\ell}(x, t) \cdot g(x, t) d x d t=1,
\end{array}\right.
$$

or equivalently, by the condition

$$
\left\{\begin{array}{l}
\mu_{s h}=\min _{\mathbf{g}} \frac{\int_{o}^{T} \int_{S_{c}} \varphi\left(p_{o}+\mu_{s h} p_{e \ell}^{\ell}\right)\|g\| d x d t}{\int_{o}^{T} \int_{S_{c}} q_{e \ell}^{\ell} \cdot g d x d t} \\
\text { among the slip rates } \mathbf{g} \text { such that } \\
\mathbf{G}=\int_{0}^{T} \mathbf{g} d t \in R S
\end{array}\right.
$$

Because of the presence of $\mu_{s h}$ in the right-hand side of (20) or of (21), the computation of $\mu_{s h}$ is slightly different from the classical analysis. Relation (19) defines a coefficient unique which is the maximum load factor ensuring the shakedown of the modified response. Indeed, for any load factor $\mu$, from the fact that

$$
\left.\varphi\left(p_{o}+\mu p_{e \ell}^{\ell}\right)\|g\|=\frac{\mu}{\mu_{s h}}\left(p_{o}+\mu_{s h} p_{e \ell}^{\ell}\right)\|g\|\right)+\frac{\mu_{s h}-\mu}{\mu_{s h}} p_{o}\|g\|
$$

it follows that $m_{s}(\mu)>1$ if $\mu<\mu_{s h}$ and $m_{s}(\mu)<1$ if $\mu>\mu_{s h}$. From Melan theorem, there is thus shakedown for the modified response at load $\mu<\mu_{s h}$.

\subsection{Kinematic approach and upper-bounds of the critical shakedown load}

For any slip rate $\mathbf{g}$ such that $\mathbf{G}=\int_{0}^{T} \mathbf{g} d t \in R S$, an associated factor $\mu_{g}$ can be computed by the relation

$$
\mu_{g}=\frac{\int_{o}^{T} \int_{S_{c}} \varphi\left(p_{o}+\mu_{g} p_{e \ell}^{\ell}\right)\|g\| d x d t}{\int_{o}^{T} \int_{S_{c}} q_{e \ell}^{\ell} \cdot g d x d t}
$$

Since

$$
m_{s}\left(\mu_{g}\right) \leq \frac{\int_{o}^{T} \int_{S_{c}} \varphi\left(p_{o}+\mu_{g} p_{e \ell}^{\ell}\right)\|g\| d x d t}{\int_{o}^{T} \int_{S_{c}} \mu_{g} q_{e \ell}^{\ell} \cdot g d x d t}=1
$$

it follows that necessarily the following estimate holds as in classical analysis

$$
\mu_{g} \geq \mu_{s h} \forall g \text { such that } \mathbf{G}=\int_{0}^{T} \mathbf{g} d t \in R S
$$

and that

$$
\mu_{s h}=\min _{\{\mathbf{g} \mid \mathbf{G}(\mathbf{g}) \in \mathbf{R S}\}} \frac{\int_{o}^{T} \int_{S_{c}} \varphi p_{o}\|g\| d x d t}{\int_{o}^{T} \int_{S_{c}}\left(q_{e \ell}^{\ell} \cdot g-p_{e \ell}^{\ell}\|g\|\right) d x d t} .
$$




\section{LIMIT LOAD IN SLIP-LIMIT ANALYSIS}

It is well known that the shakedown analysis also includes the limit analysis. The limit load $m_{l}$ deals with the set of Dirac-rates $g(x, t)=G(x) \delta_{\tau}(t)$ and thus, the limit load $\mu_{l}$ must satisfy

$$
\left\{\begin{array}{l}
\mu_{l}=\min (\mathbf{G}, \mathbf{0} \leq \tau \leq \mathbf{T}) \int_{S_{c}} \varphi\left(p_{o}(x)+\mu_{l} p_{e \ell}^{\ell}(x, \tau)\right)\|G(x)\| d x \\
\text { among rigid displacements } G(x) \text { such that } \\
\int_{S_{c}} q_{e \ell}^{\ell}(x, \tau) \cdot G(x) d x=1
\end{array}\right.
$$

or equivalently

$$
\mu_{l}=\min _{(\mathbf{G} \in \mathbf{R S}, 0 \leq \tau \leq \mathbf{T})} \frac{\int_{S_{c}} \varphi\left(p_{o}(x)+\mu_{l} p_{e \ell}^{\ell}(x, \tau)\right)\|G(x)\| d x}{\int_{S_{c}} q_{e \ell}^{\ell}(x, \tau) \cdot G(x) d x}
$$

or

$$
\mu_{l}=\min _{(\mathbf{G} \in \mathbf{R S}, \mathbf{0} \leq \tau \leq \mathbf{T})} \frac{\int_{S_{c}} \varphi p_{o}\|G(x)\| d x}{\int_{S_{c}}\left(q_{e \ell}^{\ell}(x, \tau) \cdot G(x)-p_{e \ell}^{\ell}(x, \tau)\|G(x)\|\right) d x} .
$$

Since this minimization is performed in a smaller set of slip rates, it is clear that

$$
\mu_{s h} \leq \mu_{l} .
$$

\section{THE CONROD EXAMPLE}

It is not clear that the assumption of small coupling can be available for engineering structures. For this, the example of an engine-conrod is considered to explore its validity. The conrod system is composed of a circular bearing shell $V_{1}$ in contact by pre-stress and friction with the conrod-end $V_{2}$ as shown in Fig. 1 and submitted to a cyclic rotating force
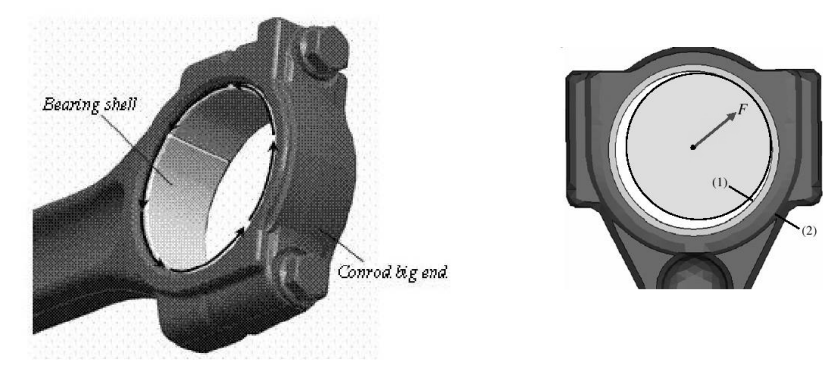

Fig. 1. A conrod bearing system of car engine under cyclic loading

$F$. In engineering design, the relative displacement of the bearing shell with respect to the conrod-end should be avoided in order to prevent possible failures of the assembly. In particular, cumulative slips might result in a failure by rigid-body displacements of the bearing shell (by translation in the axial direction or by rotation).

A simple modeling of the conrod end by two annular disks in plane strain is performed to obtain by a f.e.m analysis the response of the system under the cyclic loading, the inner solid (bearing shell) is maintained by pre-stresses and friction on the outer one 
(conrod-end). The system is in small transformation under the action of the rotating force $\mathrm{F}$ defined by the loading path $\beta(t)$ taking the values of the whole interval $(0,2 \pi)$. Global rigid displacements of the system are prevented by homogeneous displacement conditions on the section $\theta=-\pi / 2$ of the outer solid, cf. Fig. 2. Under the action of a strong rotat-

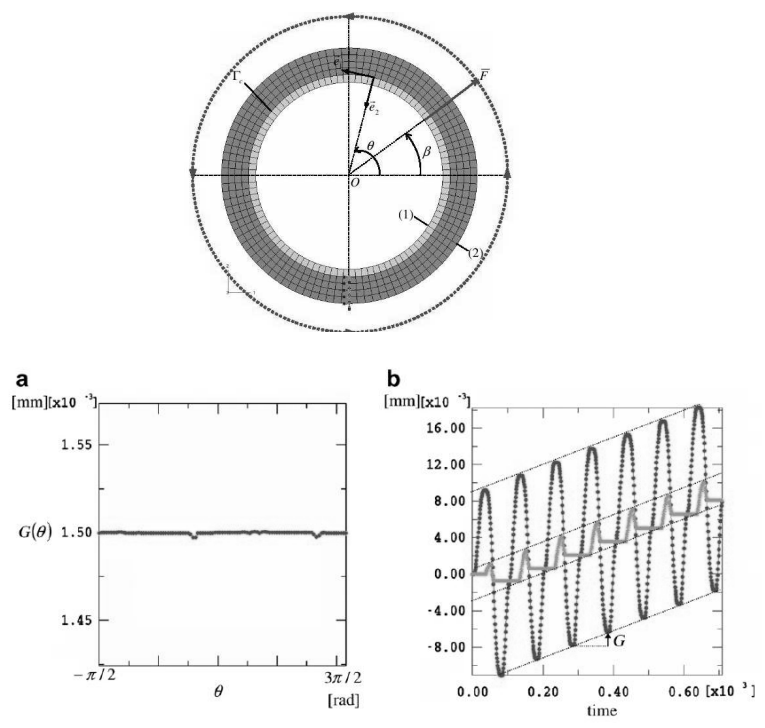

Fig. 2. 2D-simulation by f.e.m. and incremental response under a cyclic load. No shakedown at the considered load since a small rotation of the bearing shell results after each cycle

ing force, an example of non-shakedown is shown in Fig. 2a,b. Cumulative slips per cycle lead to a failure by rigid rotation of the bearing shell. The validity of the small-coupling assumption is shown in Fig.3, the local ratio $r$ is about $10 \%$.

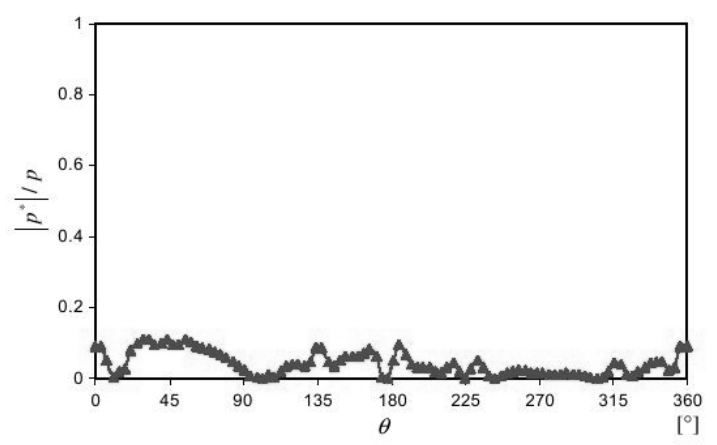

Fig. 3. Checking the small coupling assumption 


\section{CONCLUSION}

In the considered problem, the dependence of the yield limit on the amplitude of the loading is not classical. Our discussion shows that well-known general theorems of shakedown analysis and of limit analysis remain available and that static and kinematic approaches can be applied within some minor modifications. New expressions of the critical shakedown load and of the limit load are derived. The considered problem can also be found in the shakedown analysis of elastic-plastic structures under cyclic thermal loadings when the yield limit depends on the temperature.

\section{REFERENCES}

[1] N. Antoni and Q.S. Nguyen. Shakedown theorems in contact mechanics. C.R. Mecanique 336 (2008) 341-346.

[2] N. Antoni, Q.S. Nguyen, J.L. Ligier, P. Saffré, and J. Pastor. On the cumulative microslip phenomenon. EJM/A. Solids 26 (2007) 626-646.

[3] J.R. Barber, A. Klarbring, and M. Ciavarella. Shakedown in frictional contact problem for the continuum. C.R. Mecanique 336 (2008) 34-41.

[4] O. Debordes and B. Nayroles. Sur la théorie et le calcul à l'adaptation des structures élastoplastiques. J. Mécanique 20 (1976) 1-54.

[5] A. Klarbring, M. Ciavarella, and J.R. Barber. Shakedown in elastic contact problem with Coulomb friction. Int. J. Solids Structures 44 (2007) 8355-8365.

[6] W.T. Koiter. General problems for elastic-plastic solids. In J.N. Sneddon and R. Hill, editors, Progress in Solid Mechanics 4 (1960) 165-221.

[7] Q.S. Nguyen. Stability and Nonlinear Solid Mechanics. Wiley, Chichester, 2000.

[8] D.C. Pham. Shakedown kinematic theorem for elastic-plastic bodies. Int. J. Plasticity 17 (2001) $773-780$.

Received May 14, 2009

\section{PHÂN TÍCH THÍCH ỨNG-TRƯợT VÀ GIẢ THIẾT LIÊN KẾT YẾU TRONG BÀI TOÁN TIẾP XÚC MA SÁT}

Khi vật rắn tiếp xúc có ma sát dưới tác động của tải trọng chu kỳ, ứng xử thích ứng của chuyển dịch tương đối cũng được quan tâm như đối với biến dạng dẻo trong bài toán dẻo. Sự trượt tích lũy có thể dẫn đến phá hủy do dịch chuyển tương đối của các thành phần của cả hệ thống trở nên lớn trong khi đó sự trượt chu kỳ thường là không mong muốn do hiện tượng mòn và hư hỏng - là các vấn đề mỏi. Với ma sát Coulomb các định lý của Melan và Koiter nói chung là không áp dụng được trừ một số trường hợp đặc biệt. Trong bài báo này, xem xét trường hợp đặc biệt khi sự liên hợp giữa áp lực pháp tuyến và dịch chuyển trượt nhỏ. Giả thiết này có nghĩa dịch chuyển tiếp tuyến có ảnh hưởng nhỏ hoặc không ảnh hưởng đến áp lực pháp tuyến, ma ta có thể tính được từ ứng xử đàn hồi như trường hợp không liên hợp. áp lực này làm hàm của thời gian và tiêu chuẩn Coulomb dẫn đến luật về ma sát giống của Mises. Điều này chỉ ra rằng định lý của Melan và Koiter có thể áp dụng như trường hợp dẻo thông thường. Tuy nhiên, sự phụ thuộc của giới hạn chảy dẻo lên biên độ đặt tải không như thông thường và một mở rộng của cách tiếp cận tĩnh và động học được đưa ra để nhận được tải thích nghi tới hạn và tải tới hạn. Tính đúng đắn của giả thiết về sự liên hợp nhỏ được biểu diễn bằng các mô phỏng số trong các ví dụ thực tế. 